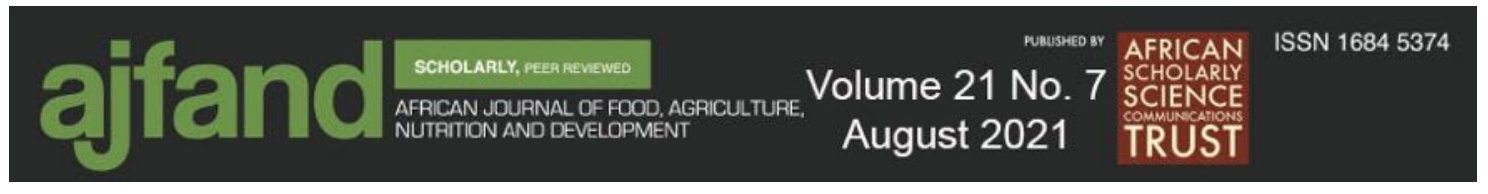

Afr. J. Food Agric. Nutr. Dev. 2021; 21(7): 18391-18403 https://doi.org/10.18697/ajfand.102.20380

\title{
NUTRITIONAL STATUS OF CHILDREN UNDER AGE FIVE IN BENUE STATE, NIGERIA
}

Seer-Uke EN ${ }^{1 *}$, Samuel ES ${ }^{2}$, Agajah ME ${ }^{1}$, Ikpato VT ${ }^{1}$, Tyoakaa AA ${ }^{1}$, Abugu $\mathrm{LI}^{2}$, Obi RI ${ }^{3}$, Ityodugh $\mathrm{JI}^{1}$ and T Kparev ${ }^{1}$

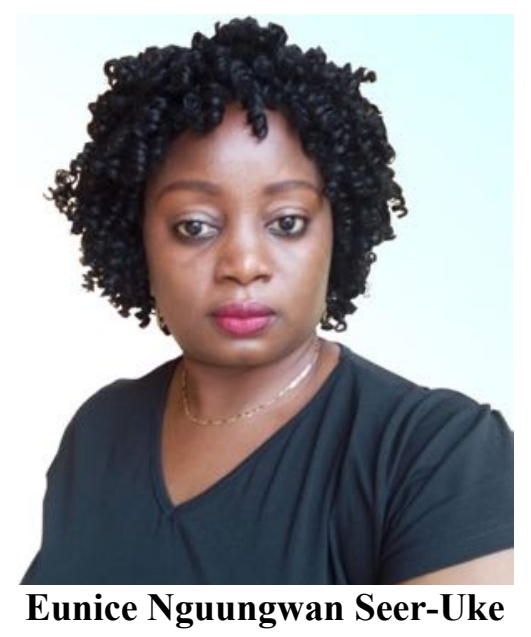

*Corresponding author email: seerukeeunice@gmail.com

${ }^{1}$ Department of Human Kinetics and Health Education, Faculty of Education, Benue State University, Makurdi, Benue State, Nigeria

${ }^{2}$ Faculty of Education, University of Nigeria Nsukka, P.M.B. 410001, Enugu State, Nigeria

${ }^{3}$ Department of Physical \& Health Education, Federal College of Education (Tech), Umunze, Anambra State, Nigeria 


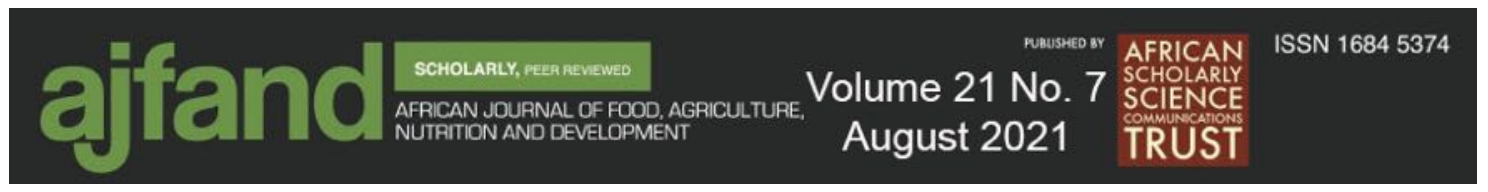

\begin{abstract}
This study aimed at determining the nutritional status of under-five children or pupils in Benue State. The objective of the study was to assess the prevalence of stunting, wasting and BMI for age of under-five children or pupils in Benue State. The participants for this study were three hundred and forty (340) under-five children or pupils who were sampled from the Early Childcare Centres (ECCs) across the primary schools in selected Local Government Areas of Benue State using multistage sampling technique consisting of three rural local government areas and three urban local government areas. Participants' stature and body mass were measured in accordance with the protocol of the International Society for the Advancement of Kinanthropometry. The body Mass Index (BMI) of the participants was derived as a ratio of weight (in kilograms) to height (in meters) squared $\left(\mathrm{kg} / \mathrm{m}^{2}\right)$ and was expressed in standard deviation unit. The frequency and percentages were adopted in analyzing the prevalence of stunting, wasting and BMI. The WHO Anthroplus Software (version 3.2.2) was used to compute the under-five nutritional status which was categorized based on WHO recommendations. The results of the study indicated that, the overall prevalence of stunting and wasting were $44 \%$ and $7.6 \%$ respectively. The overall prevalence of underweight, overweight and obesity were $6.5 \%, 12.1 \%$ and $25.9 \%$, respectively. The prevalence of stunted under-five children or children was more among rural children (49.5\%) than their urban counterparts $(38.2 \%)$. The prevalence of wasting among urban children (7.9\%) was slightly higher than their rural counterparts (7.4\%), though not significant. The prevalence of each of underweight, overweight and obesity was higher among urban children $7.9 \%, 13.8 \%$ and $27.1 \%$ than their rural counterparts which have the corresponding values of $5.3 \%, 10.6 \%$ and $24.3 \%$, respectively. It was therefore recommended that health personnel especially in Benue State should create awareness through seminars and workshops in schools, health facilities and the media on the need to provide whole meals to children and discourage the consumption of snacks or processed foods by not making it part of the children's lunch pack.
\end{abstract}

Key words: Nutritional Status, Prevalence, BMI, Under-Five Children or pupils, Benue State, Nigeria 


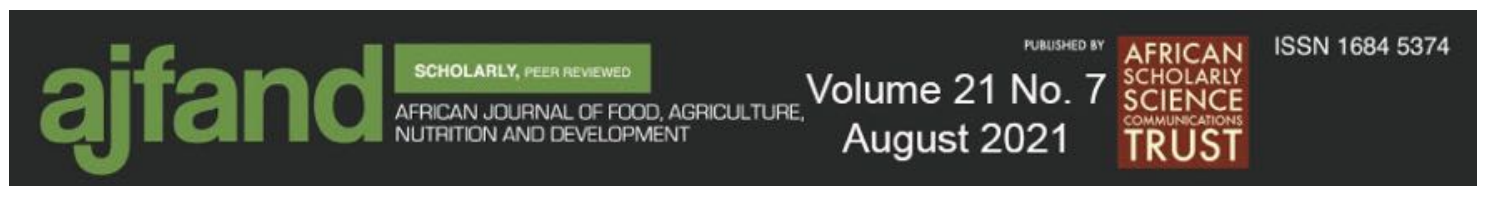

\section{INTRODUCTION}

Globally, the nutritional status of children under age five is of great concern because it determines the rates of infant morbidity and mortality. This is principally determined by the food eaten by these children and estimates the prevalence rates of stunting, wasting, underweight, overweight and obesity. Indices such as low height- for- age (stunting- an indicator of chronic undernutrition), low weight- for- height (wasting-an indicator of acute undernutrition) and low BMI for age (a composite measure to indicate both acute and chronic undernutrition) are commonly used to estimate nutritional status [1]. Worldwide, the prevalence rates of under-five children are (26\%) for stunting, $(16 \%)$ for underweight and $(8 \%)$ for wasting, respectively. The corresponding figures in Asia are 26.8\%, 19.3\%, and 10.1\%, for stunting, underweight and wasting, respectively [2]. In Iranian under-five children, 13.1\%, 7.6\%, and 4.5\% were reported for stunting, underweight and wasting, respectively [3]. Economic or social resources are linked to malnutrition, which encompasses both undernutrition and overweight/obesity. An estimated $45 \%$ of deaths of children under age five in low- and middle-income countries are linked to malnutrition [4].

The Nigeria National Health Survey (NNHS) [1] stated that, although wasting and underweight are serious, the largest malnutrition burden for sub-Saharan Africa is in fact stunting. About 37 percent of children are stunted in sub-Saharan Africa compared to a global prevalence of 25 percent [1]. The WHO classification of malnutrition prevalence considers stunting serious (or high) if levels fall within 30 to 39.9 percent, and critical (or very high) if 40 percent and above. Analysis by age groups shows that stunting increases with age, peaking at slightly above 35 percent among children in their second and third year of life.

The NNHS report further indicated that severe stunting shows a similar pattern, with the highest proportion of severe stunting in children aged 12-23 months (13.9 percent). Percentage of stunted children over two years of age is significantly higher $(p<0.001)$ than for younger children, exhibiting the consequences of stunting in early age and of long-term malnutrition. The prevalence of stunting was 32.0 percent $(95 \% \mathrm{CI}$ : 30.7 33.4) and has remained the largest burden of malnutrition with stagnated rates of above 30 percent since 2014 , and with many states in the north west and north east recording prevalence above 40 percent- the WHO critical levels. Stunting indicates a long-term nutritional problem in the country and at similar levels to that of sub-Saharan region (37 percent) with serious and irreversible consequences. Overweight prevalence at $1.2 \%$ has, however, remained below the 7 percent threshold in all the 37 domains. Overall, only 64 percent of children in Nigeria are growing healthily without being stunted or wasted. The prevalence of underweight among children aged 0-59 months was 19.9 percent (95\% CI: $21.5-23.4$ ), just at the margin of the 20 percent threshold for serious situation that it has been since 2014, higher than the global estimate of 15 percent but consistent with the rates in West and Central Africa (22\%) [1].

Similarly, the Nigeria Demographic and Health Survey shows that $37 \%$ of children under age five are stunted (too short for their age) and 17\% are severely stunted. Seven percent (7\%) are wasted (too thin for their height), with $2 \%$ being severely wasted. 


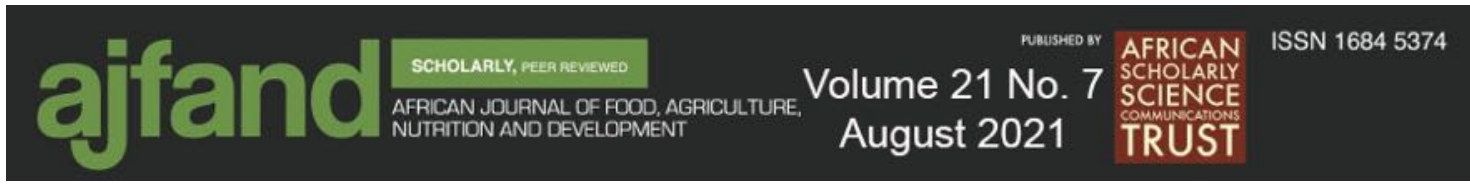

Twenty-two percent of children (22\%) are underweight (too thin for their age), and 7\% are severely underweight [5]. Only $2 \%$ of children are overweight. The prevalence of stunting increases from $19 \%$ among children less than six months to a peak of $47 \%$ among children aged 24-35 months, probably as a result of recurrent chronic illnesses [5]. This represents the impact of undernutrition in the first 1,000 days of life. Wasting, on the other hand, is more prevalent (15\%) among children aged 9-11 months [1]. The NDHS further stated that there are wide variations by zone in the prevalence of stunting. The proportion of children who are stunted is highest in the North West $(57 \%)$ and lowest in the South East (18\%). By state, stunting is most prevalent in Kebbi (66\%) and least prevalent in Anambra (14\%). In the same vain, the proportion of children who are wasted is approximately twice as high in the North east (10\%) and North West $(9 \%)$ as in the other zones (4-6\%). The prevalence of stunting, wasting, and underweight is almost twice as high among children in rural areas $(45 \%, 8 \%$, and $27 \%$, respectively) as among those in urban areas (27\%,5\%, and $15 \%$, respectively) [5].

The data presented above as documented by various scholars, UNICEF and WHO, NDHS as well as NNHS give us an idea of the nutritional status in developed and developing regions. The medical issues associated with nutritional status include deficiencies or excesses from the eating routine, obesity, dietary problems, and chronic diseases such as cardiovascular disease, hypertension, cancer, and diabetes mellitus [6]. The nutritional status of under-five children or pupils is significant because it reflects the nutritional status of a particular community [7]. This is because what happens to these children is a reflection of the whole population and is utilised to gauge the nutritional status of a population; when this good nutrition is lacking, it results in malnutrition [8].

This study is timely in Benue State because not much work has been done on this subject matter in the study area [9]. The study conducted in the State focused on overnutrition [9] with gross negligence on the prevalence of undernutrition and it did not capture other parameters of nutritional status such as stunting, wasting and underweight. The study was also conducted among children aged 9-16 years, thus neglecting the lower age range of children such as those under five years. This creates a knowledge gap that this present study is set to fill. According to NNHS and NDHS, under-five is a significant age for nutritional disorders including underweight, stunting, wasting, overweight and obesity. The purpose of the study is to investigate the prevalence of nutritional status among under-five children or pupils in Benue State, Nigeria.

\section{MATERIALS AND METHODS}

\section{Research Design}

A cross-sectional research design was used for this study.

\section{Participants}

The participants for this study were three hundred and forty (340) under-five children or pupils (0-59 months) who were selected from the Early Childcare Centres (ECCs) across the primary schools in the sampled local government areas using multistage 


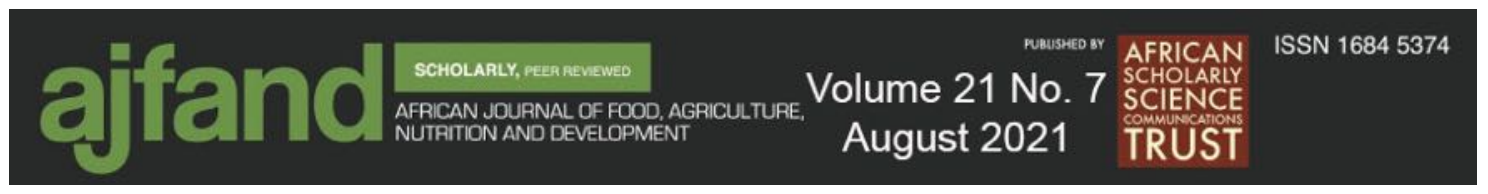

sampling technique. The local government areas were first stratified into rural and urban areas, followed by random selection of local government areas. Six local government areas were sampled out of the 23 local government areas for the studythree rural local government areas (Buruku, Gwer-East and Okpokwu) and three urban local government areas (Makurdi, Gboko and Katsina-Ala) all in Benue State. The under-five children or pupils in each of the sampled primary schools were also selected using purposive sampling technique. The sample of 340 was selected proportionate to the population of the under-five children or pupils in the sampled schools. The sample size of under-five children or pupils was determined using Taro Yamane's formula [10].

\section{Anthropometric Measurements}

Participants' stature and body mass were measured in accordance with the protocol of the International Society for the Advancement of Kinanthropometry [ISAK] [11]. Participants stood bare-footed with feet together on a level cemented floor, the upper back, buttocks and heels touching the wall, the head held erect and the eyes looking forward so that the Orbitale (lower margin of the eye socket) and the Tragion (the notch superior to the tragus of the ear) was in the Frankfort plane. The point of the greatest height to the nearest $0.1 \mathrm{~cm}$ was marked off on the wall with a flexible steel tape (Seca model Sec-206, Bournville, [ $r=0.92-0.94]$ ). For children that could not stand, their heights were determined as they lay on the level ground (recumbent height) in accordance with WHO standard. Weight was measured using a digital weighing scale (Seca digital floor scale, Sec880; Bournville, Birmingham, UK, $[r=0.75-0.85]$ ) with provision for calibration, and recorded to the nearest $0.1 \mathrm{~kg}$. The body Mass Index (BMI) of the participants was derived as a ratio of weight (in kilograms) to height (in meters) squared $\left(\mathrm{kg} / \mathrm{m}^{2}\right)$ [12]. The BMI of the pupils was expressed in standard deviation unit Z-score as recommended by WHO. Data were collected with the aid of four research assistants who were briefed by an ISAK level 3 certified personnel on how to take weight and height measurements and record appropriately and correctly in line with the parameters of the research. The instruments were calibrated after every measurement before data was collected from the next participant.

\section{Method of Data Analysis}

Data for this study were analyzed using descriptive statistics. The frequency and percentage were adopted in analyzing the prevalence of stunting, wasting and BMI. The WHO Anthroplus Software (version 3.2.2) was used to compute the under-five nutritional status which was categorized as follows: height for age $(<-3$ SD for severely stunted, <-2SD for moderately stunted, <-1SD for mildly stunted, -1SD to + 1SD for normal and $\geq+1$ SD for above normal), weight for age ( $<-3$ SD for severely wasted $<-$ $1 \mathrm{SD}$ for mildly wasted, $-1 \mathrm{SD}$ to $+1 \mathrm{SD}$ for normal and $\geq+1 \mathrm{SD}$ for above normal)), BMI (<-2SD for thinness, $<-1$ SD to $<-2$ SD for underweight, -1 SD to $<-2$ SD for normal, $+1 \mathrm{SD}$ to $<+2 \mathrm{SD}$ for overweight and $>+2 \mathrm{SD}$ for obesity) [2]. The analysis was completed using SPSS version 21. 


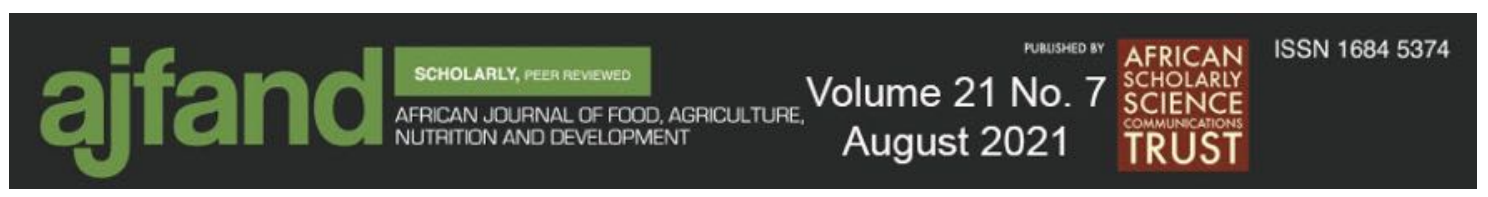

\section{RESULTS AND DISCUSSION}

The analysis as presented in Table 1 shows that there was a prevalence of stunted under-five children or pupils in Benue State (44\%). This result is of concern because children in Benue State were expected by the researchers to have lower prevalence of stunting. The high prevalence of stunting could be attributed to poor dietary habits other than unavailability of food, since there is abundant food in the state. This result is higher than the results of National Nutrition and Health Survey [1], which documented the prevalence of stunting in Nigeria to be $37 \%$. This result was surprising because, it is not only higher than the national value but also higher than other states in Nigeria. For instance, a study in South-East Nigeria, documented 9.9\% stunting prevalence [13]. In Ondo State, Nigeria, the prevalence of stunted children was $12.5 \%$ [14]. Similarly, a study in Anambra State, Nigeria indicates $15.1 \%$ overall prevalence rate of stunting [15]. The result is also higher when compared to other countries such as Iran where the prevalence rate of stunting was reported to be $9.53 \%$ [16], lower than the $16.6 \%$ prevalence rate reported by a study in Nairobi, Kenya [17]. In Northwest Ethiopia, a prevalence rate of stunting was reported as $30.7 \%$ [18], which was the only study with higher value among the foreign studies reviewed but still lower than the ones reported by this study. Stunting may start as early as in pregnancy, infancy and early childhood due to poor quality nutritional diets that may lead to inadequate nutrient intake. This is corroborated by a report that low carbohydrates intake (rice consumption), was associated with stunting [18]. The overly high prevalence of stunting noted in the present study could, therefore, reflect the cumulative effects of recurrent chronic illnesses, long term intake of poor-quality complementary diets and/or poverty since and even before birth.

The result of the study indicated a wasting prevalence of $7.6 \%$ among the under five children or pupils in Benue State. This result was not surprising as children in the study area are expected to have normal nutritional status since the state is regarded as the food basket state. The prevalence of wasted children is lower than that reported in the NDHS [1]. The result of the study is comparable to a study carried out in Anambra, Nigeria which reported that $7.7 \%$ of the children were wasted [19]. The value of wasting as obtained in this study is still more than $2.7 \%$ value reported among primary school children in Kilifi District, Kenya [17]. It is not clear whether stunting and wasting have correlation. Further studies are needed to elucidate this.

The finding of the study showed that, $6.5 \%, 12.1 \%$ and $25.9 \%$ were underweight, overweight and obese respectively. Though the underweight prevalence was lower than the national values, the prevalence rate of overweight and obesity were higher than the national values as reported by NDHS [1]. This means that overweight and obesity are the major challenges among the children in Benue State. This finding is inconsistent with a report from Anambra State which found a 10.4\% overall prevalence rate of underweight among under-five children or pupils [15]. Lower underweight rate of $2.4 \%$ was reported among preschool children aged two to five years in Aguata L.G.A of Anambra State, Nigeria [19]. The same discrepancy was found when the results were compared with other African countries. For instance, a study showed 59.7\% overall prevalence rate of underweight [18]. In Kilifi District, Kenya, overall prevalence of 


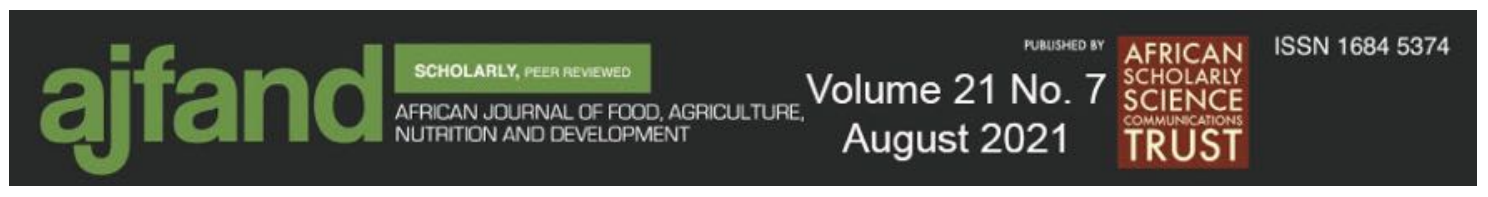

underweight was $8.3 \%$ [17]. The prevalence of 9.7\% was reported in Fars province, Iran. Another study reported an underweight prevalence rate of $52.9 \%$ among underfive children or pupils in India $[16,20]$. The relatively high prevalence in underweight among children observed in these studies could be as a result of differences in food availability.

Findings from this study revealed a prevalence rate of $12.1 \%$ for overweight among children under five years. The value obtained is surprisingly greater than the national prevalence rate of 1.5 [5], the rate of 3.2 given in Benue State by the Nigeria Multiple Indicator Cluster Survey (2017) but lower than the 19.7\% prevalence rate as reported in Benue State among children between 9-16 years [8]. The 25.9\% prevalence rate of obesity is lower than $37.2 \%$ prevalence rate reported in Osun State [20]. The result is still worrisome because the prevalence rate of underweight, obesity and overweight are higher than overall national figures documented by the NDHS [5]. Considering the position of Benue state as the food basket of the nation with abundant food, it is surprising that children in the state are still malnourished. This, therefore, calls for urgent need to address the underlying causes for this ugly trend that affects the children in this State.

Table 2 shows that the prevalence of stunted under five children or pupils was more among rural (49.5\%) children than their urban (38.2\%) counter parts. The prevalence of urban children who were wasted (7.9\%) was slightly higher than rural children $(7.4 \%)$ who were wasted though the difference is not significant. The prevalence of rural children who were underweight, overweight and obese $(5.3 \%, 10.6 \%$ and $24.3 \%)$ was lower than the prevalence of urban children which was $7.9 \%, 13.8 \%$ and $27.1 \%$ for underweight, overweight and obese respectively. The prevalence rate of stunting as found in the current study is more than the NDHS of 37\% [5], and supports the fact that stunting continues to be a major problem in Nigeria. Several factors could account for these rural-urban disparities in stunting. Primarily, this could be as a result of the differences in the presence of nutrient diverse foods in the two locations. Children from rural areas are more likely to suffer from food scarcity compared to urban children. The consumption of more processed foods and inadequate physical activity among urban children could be a potential cause of high prevalence of overweight/obesity as observed in the urban areas. The presence of processed foods in urban centres exposes urban children to a variety of nutrients to choose from and to easily supplement their diets. People in rural areas on the other hand, may limit their diets to their farm produce with little or no supplements. This is in line with a study in Iran which identified living in urban areas, and poor water supply as significant risk factors of childhood undernutrition [16]. The situation observed between urban and rural dwellers on wasting of under-five children or pupils could relate to the fact that both urban and rural settings in Benue are exposed to similar food shortages or availability. For instance, when food is available in the rural areas of Benue State, it is reflected in corresponding supply to the urban areas. Conversely, shortage of food items in the urban areas shows that, such food stuff is also scarce in the rural areas. Given the low prevalence of wasting in urban and rural areas (7.9 and 7.4, respectively), it is evident that there is a considerable level of food security in the state and hence, the prevalence of wasting observed might be as a result of environmental or health factors. This finding is at variance with a study 


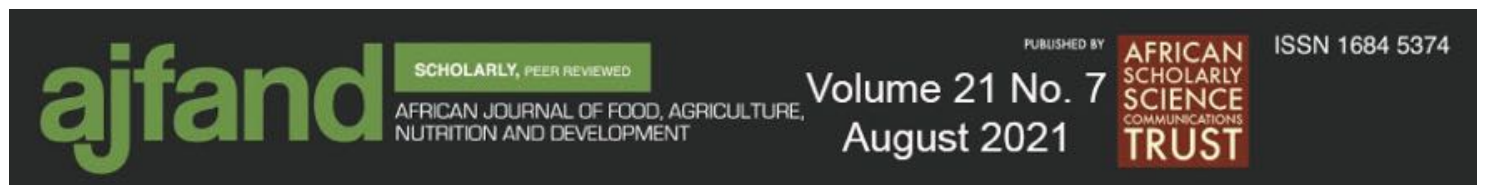

conducted in Ibadan, Nigeria which found out that wasting disproportionately affected the rural children [6]. A similar disparity, though of a higher magnitude, was also noted in the 2018 NDHS report. Conversely, a higher proportion of under-five children or who were wasted was observed in high-density urban locations [22]. The discrepancy in the finding suggests that more attention should be given to other variables such as socio-economic variables (level of education as well as occupation and income level of parents) rather than location to have a better understanding of the dynamics of nutritional disorders. This is because studies carried out in other areas of the country such as Oyo State as well as Enugu State have reported demographic and environmental variables [22] and socioeconomic factors [23], respectively as having an impact on the nutritional status of children which was beyond the scope of this study.

The result of the study should be interpreted bearing in mind that there are some difficulties associated with the sole use of BMI, for example the ratio of sitting height to standing height, age, oedema or cormic index can influence BMI. These tend to limit the usefulness of BMI as an accurate screening tool to assess nutritional status. This calls for the use of BMI in conjunction with other non-anthropometric techniques to access nutritional status. The results should also be interpreted bearing in mind that, the cross-sectional nature of the study may mask growth-related changes, which would have been discernible using a longitudinal design. In addition, the study did not control for other variables such as the socio-economic status of the parents and genetic factors. Further research is therefore needed to put these factors into consideration.

\section{CONCLUSION}

This study showed a high prevalence of stunting among under-five children or pupils of Benue State. The prevalence of wasting, underweight, overweight and obesity was moderate. Stunting was higher in the rural areas while overweight/obesity was more prevalent among the urban children. Wasting was higher in urban areas though not statistically significant.

In this present study, many children suffer from the double burden of malnutrition in which undernutrition and overweight/obesity co-exist within the same community or even the same household.

Based on the outcome of the current study, the following recommendations were made:

1. Parents should provide their children with adequate nutrition that will enhance the full development of children right from birth. This could be achieved through exclusive breastfeeding, extended breastfeeding time, provision of whole meals. These could reduce the consumption of snacks and long-term intake of poor-quality complementary diets that bring about stunted growth.

2. Health institutions through their antenatal and postnatal programmes should educate mothers on the need for adequate and timely feeding of their children. This will enable the mothers to feed their children on time to prevent the children from being underweight. 


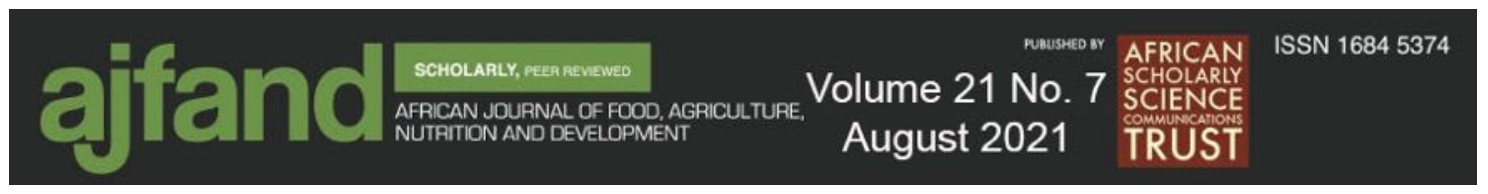

\section{ACKNOWLEDGEMENTS}

Our deepest gratitude goes to all parents, caregivers, school administrators and the under five children or pupils who participated in this study.

\section{ETHICAL CONSIDERATION}

The postgraduate research committee of the Faculty of Education, University of Nigeria, Nsukka reviewed and approved the protocol for this study. Informed consent was also obtained from the parents of the pupils and the head teachers of the respective schools since the participants were under-aged for self-consent. To protect the identities of the participants, numbers were assigned in place of names. The parents and the head teachers were assured of utmost confidentiality of the research. 


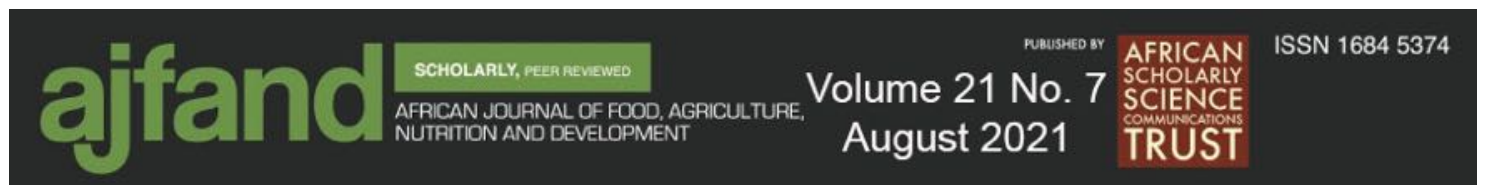

Table 1: Prevalence of stunting, wasting and BMI for age of Under Five in Benue State $(n=340)$

\begin{tabular}{lll}
\hline Variable & Frequency (f) & Percentage (\%) \\
\hline Height for Age Category & & \\
\hline Stunted & 151 & 44.4 \\
Non stunted & 189 & 55.6 \\
Total & $\mathbf{3 4 0}$ & $\mathbf{1 0 0 . 0}$ \\
Weight for Age Category & & \\
Wasted & 26 & 7.6 \\
Non wasted & 314 & 92.4 \\
Total & $\mathbf{3 4 0}$ & $\mathbf{1 0 0 . 0}$ \\
BMI for Age Category & & \\
Underweight & 22 & 6.5 \\
Normal weight & 189 & 55.6 \\
Overweight & 41 & 12.1 \\
Obese & 88 & 25.9 \\
Total & $\mathbf{3 4 0}$ & $\mathbf{1 0 0 . 0}$ \\
\hline
\end{tabular}

Table 2: Prevalence of Stunting, wasting and BMI for Age (underweight, normal weight, overweight and obesity) of Under Five Based on Location $(n=340)$

\begin{tabular}{lllll}
\hline Variable & \multicolumn{2}{c}{ Rural } & \multicolumn{1}{c}{ Urban } \\
\hline Height for Age & Frequency (f) & Percentage (\%) & Frequency (f) & Percentage (\%) \\
Stunted & 93 & 49.5 & 58 & 38.2 \\
$\begin{array}{l}\text { Not Stunted } \\
\text { Weight for height }\end{array}$ & 95 & 50.5 & 94 & 61.8 \\
Wasted & 14 & & & \\
Not Wasted & 174 & 7.4 & 12 & 7.9 \\
BMI for Age & & 92.6 & 140 & 92.2 \\
Underweight & 10 & 5.3 & & \\
Normal Weight & 107 & 56.9 & 12 & 7.9 \\
Overweight & 20 & 10.6 & 13.8 & 53.9 \\
Obese & 51 & 24.3 & 37 & 37 \\
\hline
\end{tabular}




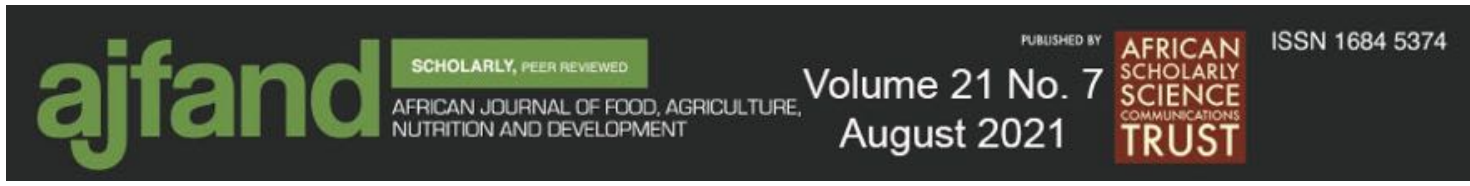

\section{REFERENCES}

1. National Nutrition and Health Survey (NNHS). Report on the nutrition and health situation of Nigeria. Abuja: National Bureau of Statistic. 2018. Available from https://www.unicef.org/nigeria/reports/national-nutrition-and-health-surveynnhs-2018 Accessed on 15th July, 2020.

2. UNICEF-WHO-The World Bank. Project (2012). Joint child malnutrition estimates - Levels and trends. Global Database on Child Growth and Malnutrition. 2012. Available from https://www.who.int/nutgrowthdb/estimates2012/en/ Accessed on 12 th December, 2019.

3. Houshyarrad A, Dorosti Motlagh AR, Kalantari N, ABD Elahi M and M Abtahi Prevalence of stunting, underweight, wasting and overweight among Iranian under-five-year-old Children (2000-2002). J Nutr Sci F Tech. Winter 2009; 3, 4(11): 49-56.

4. Black R.E, Victora CG, Walker SP, Bhutta ZA, Christian P, de Onis M, Ezzati M, Grantham-McGregor S, Katz $\mathbf{J}$ and $\mathbf{R}$ Martorell Maternal and child undernutrition and overweight in low-income and middle-income countries. Lancet. 2013;382:427-451. https://doi.org/10.1016/S0140-6736(13)60937-X

5. National Population Commission (NPC). Nigeria and ICF. 2019. Nigeria Demographic and Health Survey (NDHS) 2018. Abuja, Nigeria, and Rockville, Mayland, USA. NPC and ICF. Available from https://www.dhsprogram.com/pubs/pdf/FR359/FR359.pdf Accessed on 15 th March, 2020.

6. Ijarotimi BT, Adebiyi OA and A Fatiregun Urban-Rural Disparities and Determinants of nutritional Status of Under-Five Children: An Example of Akinyele Local Government Area, Ibadan. IJTDH 2016;16(1): 1-11. Available from https://journalijtdh.com/index.php/IJTDH/article/view/20243 Accessed on $10^{\text {th }}$ January, 2020.

7. John J, Wolfenstetter SB and CM Wenig An economic perspective on childhood obesity: recent findings on cost of illness and cost effectiveness of interventions. Nutrition, 2012; 28(9): 829-839. Available from https://pubmed.ncbi.nlm.nih.gov/22452837/ Accessed on 10 $0^{\text {th }}$ January, 2020.

8. Adye ET Prevalence of malnutrition among pre-school children in, South-east Nigeria. Italian Journal of Pediatrics, 2015; 40: 75-82.

9. Musa DI, Toriola AL, Monyeki MA and B Lawal Prevalence of childhood and adolescent overweight and obesity in Benue State, Nigeria. Tropical Medicine \&International Health: Trop Med \& Int Health. 2012; 17: 10. Available from https://pubmed.ncbi.nlm.nih.gov/22974459/ Accessed on 15 th July, 2017. 


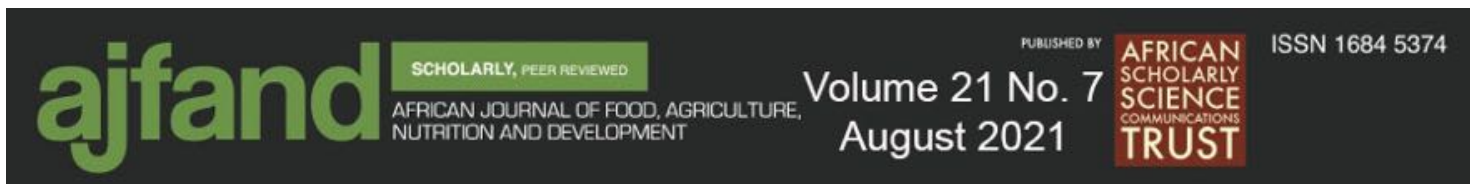

10. Taro Y Statistics: An Introductory Analysis $\left(2^{\text {nd }}\right.$ ed). New York: Harper and Row. 1967.

11. ISAK. International Standards for Anthropometric Assessment. South Africa, The Author. 2001

12. Plowman AS and DL Smith Exercise physiology for health, fitness and performance ( $2^{\text {nd }}$ ed.). San Francisco: Benjamin Cunnings. 2003.

13. Manyike PC, Chinawa JM, Ubesie A, Obu HA, Odetunde OI and AT

Chinawa Prevalence of malnutrition among pre-school children in South-East

Nigeria. Italian Journal of Pediatrics, 2014; 40: 23-33. Available from https://ijponline.biomedcentral.com/articles/10.1186/s13052-014-0075-5 Accessed on 20 ${ }^{\text {th }}$ March, 2020.

14. Akorede QL and OM Abiola Assessment of nutritional status of under-five children in Akure South Local Government, Ondo State Nigeria. IJRRAS, 2013; 4: 14-24. Available from https://www.arpapress.com/Volumes/Vol14Issue3/IJRRAS_14_3_24.pdf Accessed on 15th January, 2020.

15. Nkiru NE, Prosper OUA, Christian CI and DA Echendu Comparative analysis of the nutritional status of under-five children and their mothers in rural and urban areas of Anambra State, Nigeria. EJNFS, 2015; 5:190-201. Available from https://doi.org/10.9734/EJNFS/2015/17392 Accessed 15 $5^{\text {th }}$ January, 2020.

16. Kavosi E, Rostami ZH, Kavosi Z, Nasihatkon A, Moghadami M and $M$ Heidari Prevalence and determinants of under-nutrition among children under six: a cross-sectional survey in Fars province, Iran. IJHPM, 2014; 3: 71-76. Available from https://doi.org/10.15171/ijhpm.2014.63 Accessed 15 $5^{\text {th }}$ January, 2020 .

17. Tunje DS Prevalence and determinants of malnutrition among primary school children in Kilifi District, Kenya. A dissertation presented in partial fulfilment of the requirements for the degree of master of medicine in paediatrics and child health in the university of Nairobi, Kenya. 2017. Available from http://erepository.uonbi.ac.ke/bitstream/handle/11295/95593/Tunje_Prevalence\% 20and $\% 20$ Determinants $\% 20$ of $\% 20$ Malnutrition $\% 20$ Among $\% 20$ Primary $\% 20 \mathrm{Sch}$ ool $\% 20$ Children $\% 20 \mathrm{in} \% 20 \mathrm{Kilifi} \% 20$ District $\% 2 \mathrm{c} \% 20 \mathrm{Kenya}$.pdf? sequence $=4 \&$ is Allowed=y Accessed on 15h March, 2020.

18. Mekonnen H, Tadesse $\mathbf{T}$ and $\mathbf{T}$ Kisi Malnutrition and its correlates among rural primary school children of Fogera District, Northwest Ethiopia. J Nutr Disorders Ther., 2013; S12. Available from https://www.longdom.org/openaccess/malnutrition-and-its-correlates-among-rural-primary-school-children-offogera-district-northwest-ethiopia-2161-0509.S12-002.pdf Accessed on 13 ${ }^{\text {th }}$ February, 2020. 


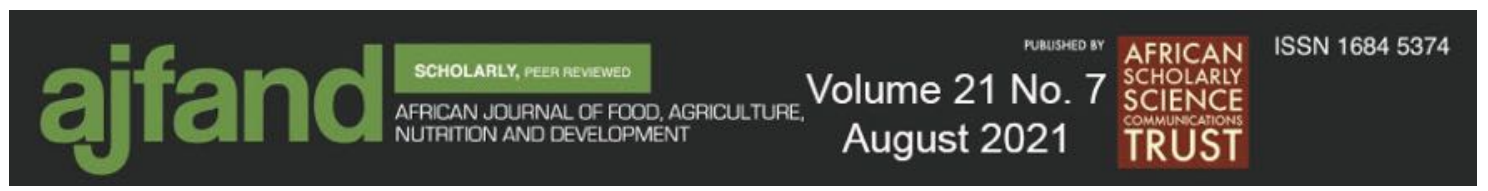

19. Okoroigwe FC and EC Okeke Nutritional status of preschool children aged 2 years in Aguata L.G.A of Anambra State, Nigeria. International Journal of Nutrition and Metabolism, 2009; 1: 9-13. Available from https://citeseerx.ist.psu.edu/viewdoc/download?doi=10.1.1.964.9603\&rep=rep1\& type $=$ pdf Accessed on $10^{\text {th }}$ February, 2020.

20. Stalin P, Bazroy J, Dimri D, Singh Z, Senthilvel V and S Sathyanarayanan Prevalence of underweight and its risk factors among under five children in a rural area of Kancheepuram District in Tamil Nadu, India. J. Med. Dent. Sci., 2013; 3: 71-74.

21. Sabageh AO and EO Ojofeitimi Prevalence of obesity among adolescents in Ile-Ife, Osun state, Nigeria using body mass index and waist hip ratio: A comparative study. Niger Med J, 2013; 54: 153-156. Available from https://www.ncbi.nlm.nih.gov/pmc/articles/PMC3719239/ Accessed on $10^{\text {th }}$ February, 2020.

22. Awoyemi TT, Odozi JC and AA Ogunniyi Environmental and Socioeconomic Correlates of Child Malnutrition in Iseyin Area of Oyo State, Nigeria. Food and Public Health, 2012; 2: 92-98. Available from http://article.sapub.org/10.5923.j.fph.20120204.02.html Accessed on 12 $2^{\text {th }}$ December, 2019.

23. Igbokwe O, Adimorah G, Ikefuna A, Ibeziako N, Ubesie A, Ekeh C and K Iloh Socio-demographic determinants of malnutrition among primary school aged children in Enugu, Nigeria. Pan Afr. Med. J. 2017; 28:248. Available from https://www.ncbi.nlm.nih.gov/pmc/articles/PMC6011006/ Accessed on 29th November, 2019. 